Research Article

\title{
Energy Accumulation and Dissipation of Coal with Preopening under Uniaxial Loading
}

\author{
Xin Wei, ${ }^{1,2}$ Hao $\mathrm{Hu}^{\mathrm{D}},{ }^{3}$ and Yang $\mathrm{Li}^{1}$ \\ ${ }^{1}$ Engineering Laboratory of Deep Mine Rockburst Disaster Assessment, Shandong, Jinan, China \\ ${ }^{2}$ Shandong Province Research Institute of Coal Geology Planning and Exploration, Shandong, Jinan, China \\ ${ }^{3}$ State Key Laboratory of Mining Response and Disaster Prevention and Control in Deep Coal Mines, \\ Anhui University of Science and Technology, Anhui, China \\ Correspondence should be addressed to Hao Hu; 2017040@aust.edu.cn
}

Received 26 December 2020; Revised 3 January 2021; Accepted 9 January 2021; Published 22 January 2021

Academic Editor: Guangchao Zhang

Copyright (c) 2021 Xin Wei et al. This is an open access article distributed under the Creative Commons Attribution License, which permits unrestricted use, distribution, and reproduction in any medium, provided the original work is properly cited.

\begin{abstract}
Energy accumulation and dissipation play an important role during the entire process of rock failure. Some flaws, such as preexisting holes, will influence energy accumulation and dissipation. In order to investigate the energy evolution of coal specimen with preexisting holes under uniaxial compression through numerical approaches, the particle simulation method was used in numerical simulations. In this paper, the energy evolution of coal specimen was theoretically analyzed, and the influence of different hole arrangement, such as diameter, spacing, angle, and number, on the evolution characteristics of energy was also discussed. At the same time, the arrangement of the artificial boreholes for preventing the rockburst was explored. The results show that, compared with the intact coal specimen, the change of diameter, spacing, angle, and the number of holes weakened the coal specimen's capacity to store energy and release strain energy. When the diameter, the vertical distance, and relative angle of preexisting holes were $15 \mathrm{~mm}, 10 \sim 15 \mathrm{~mm}$, and $60^{\circ}$, respectively, the energy storage limit reached optimal value. For arrangement of the artificial boreholes, the diameter, spacing, and angle can be designed on the basis of those optimal values. This study has a guiding significance in designing the arrangement of the artificial boreholes for mitigation of rockburst.
\end{abstract}

\section{Introduction}

At present, with the exploitation of coal resources, some longwall faces required large-scale excavation of deep coal seam under the high in situ stress $[1,2]$. During mining in deep coal seam, rockburst, which is a sudden manifestation of the release of strain energy stored in the coal seam, often occurs [3-6]. As a human activity-induced geologic hazard, rockburst not only threatens the stability and safety of the surrounding structures but also endangers the lives of nearby workers $[7,8]$. In order to mitigate rockburst hazard, destressing techniques, such as drilling through large-diameter holes and stress-relief blasting, were often implemented to destroy the structural integrity of the coal and then reduce the mining-induced energy accumulation $[9,10]$. For drilling through the large-diameter hole technique, the number and spacing of the hole were artificially drilled and arranged in the roadway. It is not difficult to find out that research on the energy accumulation and dissipation of coal specimen with preexisting hole defect (CSPHDD) has great significance for mitigation of rockburst events by drilling through the large-diameter hole technique.

Currently, numerous studies have been done in different methods to study the failure mechanism of CSPHDD. Theoretical analysis methods are often utilized based on elastic-plastic mechanics and damage mechanics [11-13]. Many studies employ the theoretical analysis method for understanding the failure mechanism of rock mass with preexisting holes. Laboratory test is one of the important methods to study the failure mechanism. Fakhimi et al. [14] performed a biaxial compression test on a sandstone specimen with a circular opening to simulate a loading-type failure around an underground excavation in brittle rock. Li et al. [15] carried out the uniaxial compression tests of 
granite samples containing holes and researched the crack propagation around the hole. Yang et al. [16] studied the crack propagation of sandstone specimen containing a hole by indoor uniaxial compression test and studied the preexisting hole's effect on the stress-strain curve. Liu et al. [17] researched the influence of the hole on the mechanical properties of rock-like materials by indoor uniaxial compression test and then concluded that the preexisting holes can reduce the rockburst tendency of coal mass. Lin et al. [18] examined crack initiation, coalescence mechanisms, and failure behavior of granite with preexisting multiple holes under uniaxial compression and discussed the influence of multiple holes on peak strengths. In recent years, an increasing number of studies have been done with different numerical methods. Many researchers analyzed the failure mechanism of CSPHDD with numerical modeling methods for the past few years. The most commonly used models were built on discrete element and finite element. Cho et al. [19] studied damage development of rock mass with preexisting hole using particle flow code. Wong et al. [20] used material failure process analysis code to investigate the splitting failure, the failure modes, and strength characterization of brittle solids containing a single hole with varying diameters and sample widths. Zhao et al. [12] used progressive elastic damage method realistic failure process analysis (RFPA) to investigate stress redistribution of rocklike materials with an open hole under uniaxial compression. Zhang et al. [21] simulated damage procession of marble specimen with preexisting a hole and discussed the effect of hole on the failure mechanism of rock mass. On this basis, they explored the mechanism of slabbing failure and rib spalling around excavation boundary in deep high stress. Apparently, the above research mostly focused on the macroscopic damage and microcrack propagation of the rock mass with preexisting holes. It can be concluded that less attention was paid to the study of energy concentration and dissipation during the deformation and failure process of the CSPHDD. Due to the experimental limitations, details of energy evolutions could not always be observed and assessed comprehensively. To contribute to this field of research, a numerical approach based on the particle element model was used in the present study.

In this paper, firstly, a series of laboratory tests were conducted to study the macromechanical properties of intact coal specimens. Secondly, the microparameters for PFC2D particle flow model were acquired. Thirdly, this paper analyzed the evolution mechanism of energy and studied energy accumulation and dissipation of coal specimen with different hole arrangement under uniaxial compression. Finally, the implementation of DLDH for preventing rockburst was discussed. This study has slight guidance for the mitigation of rockburst during mining in deep coal seam.

\section{Model Building and Determination of the Microparameters}

2.1. Test Samples and Experimental Apparatus. In order to validate the rock mechanics parameters of coal samples, coal located in a deep coal roadway in the Xinhe mine was used for conventional triaxial compression experiments. Xinhe mine was located in the Jining mining area, China, with a depth of about $1000 \mathrm{~m}$. Coal blocks were collected from the site and further machined in the laboratory to obtain coal samples. The preparation and testing procedure of coal samples followed the standard testing methods by the International Society for Rock Mechanics [22]. Those specimens were cut into a cylindrical shape with a ratio of height to diameter of $2: 1$, with $100 \mathrm{~mm}$ in length and $50 \mathrm{~mm}$ in diameter, as shown in Figure 1(a). Then, the triaxial and uniaxial compression experiments were carried out by using an MTS815.03 full-digitally servo-controlled rock mechanics testing machine in the State Key Laboratory of Mining Disaster Prevention and Control Cofounded by Shandong Province and the Ministry of Science and Technology, Shandong University of Science and Technology, China.

The stress-strain curve and the failure characteristics at postpeak stage were shown in Figure 1. Figure 1 showed that the failure pattern of the coal specimen was the combination of axial splitting and local shearing. Besides, the fracture process developed very quickly at the postpeak stage, which indicated that the rock's mechanical behavior was brittle. Table 1 showed some correlative rock mechanics parameters, such as elastic modulus $E$, Poisson ratio $v$, uniaxial compressive strength (UCS), cohesion $c$, and friction angle $\phi$.

2.2. Determination of the Microparameters. For PFC2D, it provided a numerical method that can reproduce qualitatively almost every mechanical mechanism and phenomenon that occurs in rocks [23-25]. The bonded particle model (BMP) was adopted to create a numerical model of coal samples. Since typical PFC2D models required some micromechanical parameters, which cannot be measured directly using existing laboratory tests, the trial-and-error method was used to determine some microparameters, such as parallel-bond modulus, parallel-bond mean normal strength, and parallel-bond mean shear strength of the parallel bond [23, 25]. Those parameters were listed in Table 2. The results of the indoor rock mechanics test and numerical simulation were compared in Table 1.

In Figure 1, it can be observed that the numerical results duplicated the brittle failure under uniaxial compression. For example, the stress-strain curve dropped down immediately after it reaches the peak strength. Table 2 shows the micromechanical parameters adopted in this study to characterize the failure process of the coal specimen. These parameters can lead to the sample-level parameters, as shown in Table 1. Apparently, the minimum error of the corrected USC was $6.04 \%$ and the maximum error of the corrected friction angle was only $19.04 \%$. This difference was caused by the limitations of PFC2D models. In brief, those macroscopic mechanical parameters obtained from the numerical simulation were in good agreement with the experimental results.

\section{Analysis of Energy Evolution during the Deformation and Failure of Coal Specimen}

It is widely known that energy conversion is the basic rule of materials. Coal is a special kind of rock material, and 


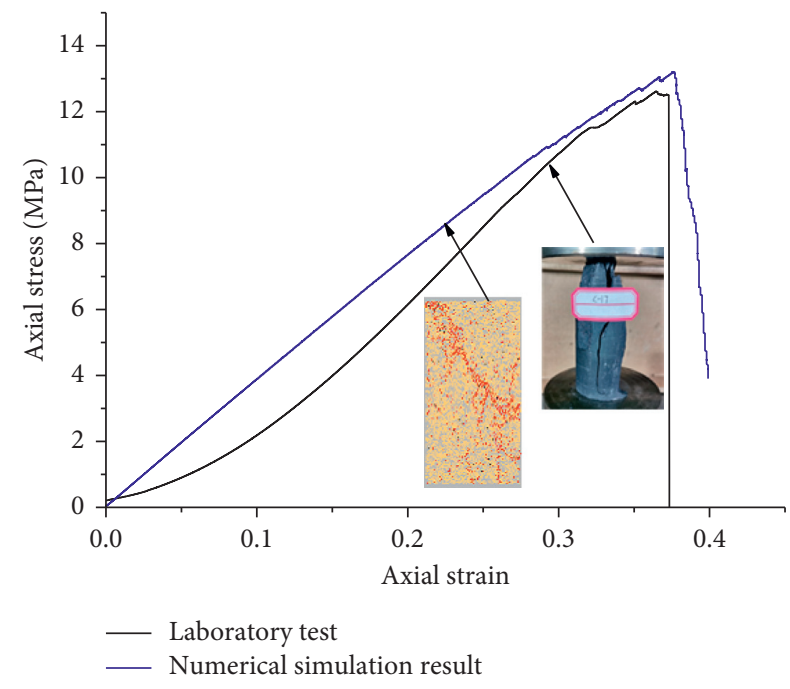

Figure 1: The stress-strain curves of coal under uniaxial compression.

TABLE 1: Comparison of laboratory test and numerical simulation results.

\begin{tabular}{lccccc}
\hline & USC/MPa & $v$ & $E(\mathrm{GPa})$ & $c(\mathrm{MPa})$ & $\phi$ (deg.) \\
\hline Experimental & 28.1 & 0.23 & 8.15 & 9.56 & 24.41 \\
Numerical & 26.4 & 0.215 & 7.35 & 8.89 & 19.76 \\
Error (\%) & $6.04 \%$ & 6.51 & 9.81 & 7.01 & 19.04 \\
\hline
\end{tabular}

TABle 2: Mesoscopic physics-mechanical parameters of coal sample.

\begin{tabular}{lc}
\hline Micromechanical parameters & Values \\
\hline Density $\left(\mathrm{kg} \cdot \mathrm{m}^{-3}\right.$ ) & 1760 \\
Average particle radius $(\mathrm{mm})$ & 0.4231 \\
Ratio of largest to smallest radii & 1.766 \\
Particle-particle contact modulus $(\mathrm{GPa})$ & 5.5 \\
Particle stiffness ratio & 2.0 \\
Particle friction coefficient & 0.8 \\
Parallel-bond modulus (GPa) & 5.5 \\
Parallel-bond stiffness ratio & 2.0 \\
Parallel-bond mean normal strength $(\mathrm{MPa})$ & 15 \\
Parallel-bond normal strength and standard deviation & 5 \\
(MPa) & 5 \\
Parallel-bond mean shear strength (MPa) & 17 \\
Parallel-bond shear strength and standard deviation & 5 \\
$(\mathrm{MPa})$ & 5 \\
\hline
\end{tabular}

considering that a unit volume coal element is a linearly elastic, homogeneous, and isotropic material, it will produce deformation under the action of external force. During the entire deformation and failure of a unit volume coal element, from loading to failure, the damage or failure of materials is always accompanied by the energy accumulation and dissipation. The failure of this unit volume coal element is a result of the dissipation and release of energy. At the same time, the stress-strain curves and strain energy of the unit volume coal element will be altered as shown in Figure 2. From state A to state B, elastic deformation is produced under the action of external force, and all the work done by the external force is transferred to strain energy of the unit volume coal element. During increasing loading, from state A to state $\mathrm{B}$, the deformation transforms from elastic to plastic deformation, and internal damage within this unit volume coal element begins to appear and later develops. During this process, some energy is dissipated and the rest energy is still stored in the form of releasable strain energy. Once the releasable strain energy in a unit volume coal element exceeds the limit value which the coal element can store, the coal element will be destroyed. From state B to state $C$, the dissipation energy begins to rise accompanied by a large energy release. In a word, energy transformation during coal element falls into three stages: energy accumulation, energy dissipation, and energy release, as shown in Figure 3. During deformation and failure of a unit volume coal element, the energy balance equation can be described by the following formula:

$$
E_{w}=U_{e}+U_{d},
$$

where $E_{w}$ is the total accumulated work done by an external force; $U_{e}$ is the total strain energy stored in the coal body; $U_{d}$ is the dissipated energy during the entire inelastic deformation.

In PFC2D models, throughout the loading process, the uniaxial compression is achieved by adjusting the upper and bottom wall velocity using a numerical servo mechanism that is implemented by the FISH functions [24]. Therefore, all the work done by external force $E_{w}$ can be determined by the following equation:

$$
E_{w}=E_{\text {pre }}+\left(F_{1} \Delta U_{1}+F_{2} \Delta U_{2}\right)
$$

where $E_{\text {pre }}$ is the input energy at the end of the time step $n$; $F_{1}, F_{2}$ are the force of the upper and bottom walls acting on particles at the end of the time step $n+1$, respectively; $\Delta U_{1}, \Delta U_{2}$ are the axial displacement of the upper and bottom walls at the end of the time step $n+1$, respectively.

In the BMP model, particles are to be bonded together at contacts (in Figure 4). These bonds establish an elastic interaction between particles and each parallel bond can be envisioned as a set of elastic springs with constant normal and shear stiffness [24]. Therefore, the total strain energy $U_{e}$ can be stored in the form of bond energy $E_{p b}$ and contact strain energy $E_{c}$. In this paper, the total strain energy $U_{e}$ may be expressed by the following equation:

$$
\begin{aligned}
U_{e} & =E_{\mathrm{pb}}+E_{c}, \\
E_{\mathrm{pb}} & =\frac{1}{2} \sum_{N_{\mathrm{pb}}}\left(\frac{\left|\bar{F}_{i}^{n}\right|^{2}}{\left(A \bar{k}^{n}\right)}+\frac{\left|\bar{F}_{i}^{s}\right|^{2}}{\left(A \bar{k}^{s}\right)}+\frac{\left|\overline{M_{3}}\right|^{2}}{\left(I \bar{k}^{n}\right)}\right), \\
E_{c} & =\frac{1}{2} \sum_{N_{c}}\left(\frac{\left|F_{i}^{n}\right|^{2}}{k^{n}}+\frac{\left|F_{i}^{s}\right|^{2}}{k^{s}}\right),
\end{aligned}
$$

where $N_{p b}$ is the number of parallel bonds; ${\overline{F_{i}}}_{i}^{n},{\overline{F_{i}}}^{s}$, and $\overline{M_{3}}$ are the magnitudes of the normal, shear components, and moment of the parallel bonds; $\bar{k}^{n}$ and $\bar{k}^{s}$ are the normal and 


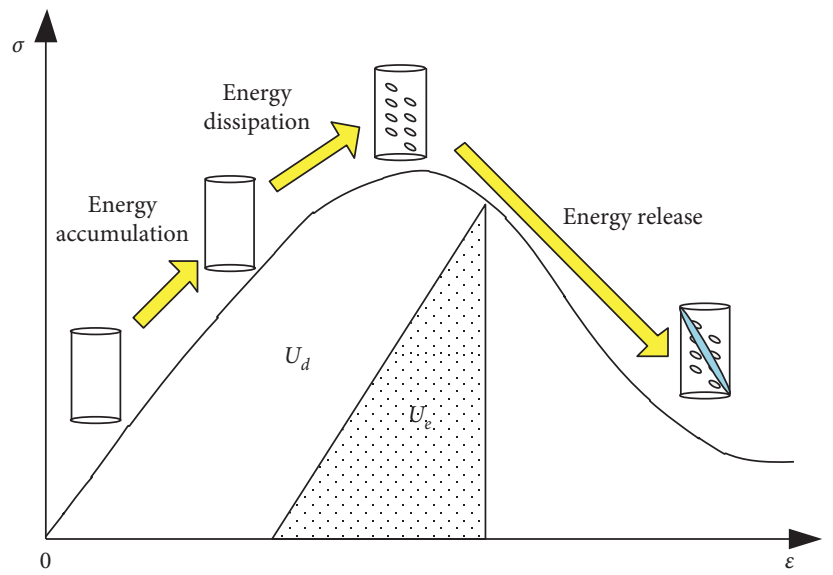

Figure 2: Relationship between energy change and stress-strain state of unit volume coal element.

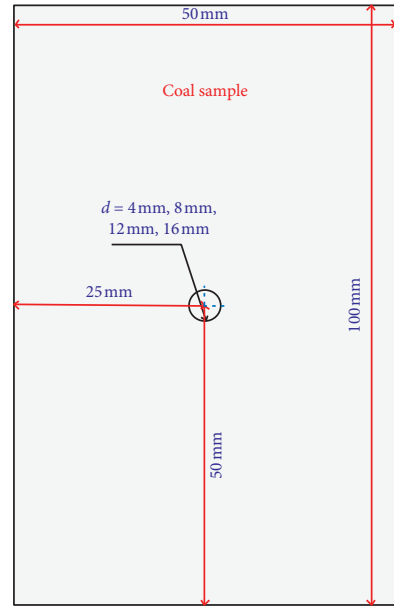

(a)

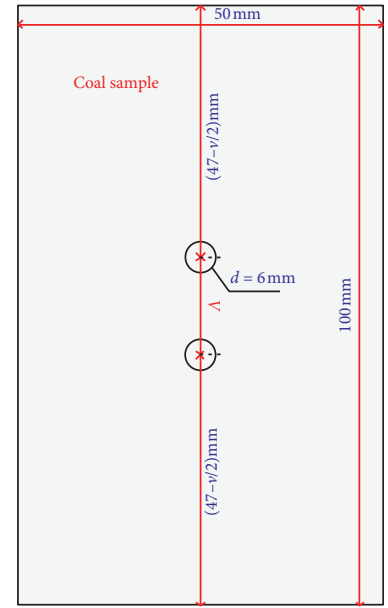

(b)

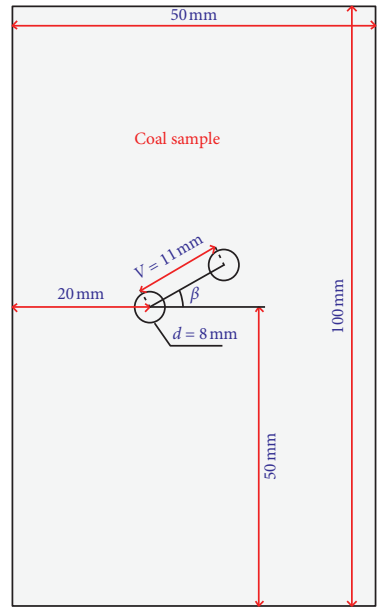

(c)
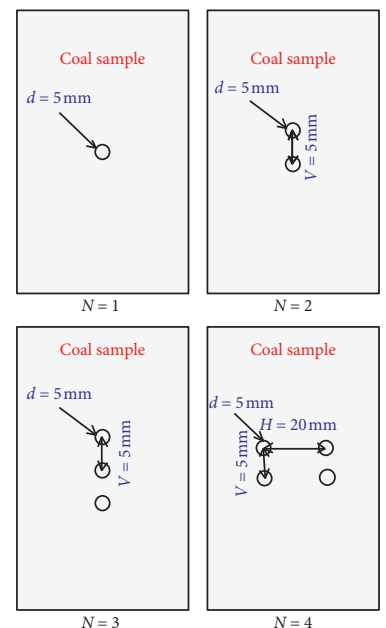

(d)

FiguRE 3: Sketch of hole arrangement in coal sample: (a) different hole diameter; (b) different hole spacing; (c) different hole relative angle; (d) different hole number.

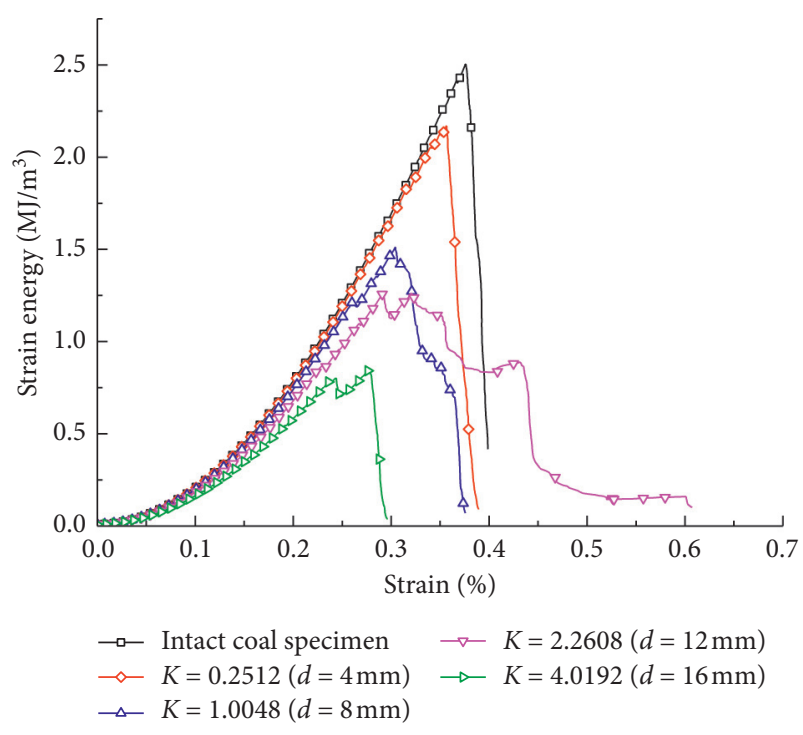

FIGURE 4: Curve of strain energy $U_{e}$ and strain. shear stiffness and rotational inertia of the parallel bonds; $A$ is the cross-sectional area of the parallel bonds; $N_{c}$ is the number of contacts; $F_{i}^{n}$ and $F_{i}^{s}$ are the magnitudes of the normal and shear components of the contact force; and $k_{n}$ and $k_{s}$ are the normal and shear-contact stiffness.

With the aid of the PFC particle flow program, all works done acting on the particle model by the external force $E_{w}$, the bond energy $E_{p b}$, and the contact strain energy are calculated, respectively. Then, from formulae (1) and (3), the dissipated energy $U_{d}$ can be obtained.

\section{Energy Evolution of Coal Samples under Uniaxial Compression}

4.1. Numerical Simulation Program Scheme. In order to explore the energy evolutions law of coal specimen under uniaxial compression, four simulation schemes are designed. Then, according to calibrated mesoscopic physic-mechanical parameters, the numerical models with different hole arrangement were established, respectively. 
Scheme one: as shown in Figure 3(a), the diameter $d$ of the preexisting hole was $4 \mathrm{~mm}, 8 \mathrm{~mm}, 12 \mathrm{~mm}$, and $16 \mathrm{~mm}$, respectively. The numerical models both were $100 \mathrm{~mm}$ in height and $50 \mathrm{~mm}$ in width.

Scheme two: in Figure 3(b), the vertical distances $V$ between two preexisting holes were $5 \mathrm{~mm}, 10 \mathrm{~mm}, 15 \mathrm{~mm}$, and $25 \mathrm{~mm}$, respectively. Moreover, the diameter of the hole was $8 \mathrm{~mm}$ and the size of the models was the same as the above.

Scheme three: in Figure 3(c), the relative angle of preexisting holes $\beta$ was $0^{\circ}, 30^{\circ}, 60^{\circ}$, and $90^{\circ}$, respectively. The diameter of each hole was $5 \mathrm{~mm}$ and the vertical spacing of holes was $10 \mathrm{~mm}$. Moreover, the relative angle of preexisting was the angle between the centers of two holes and the horizontal direction. And the size of the models was also the same as the above.

Scheme four: in Figure 3(d), the number of preexisting holes $N$ was one, two, three, and four, respectively. The diameter of each hole was $5 \mathrm{~mm}$ and the vertical spacing and horizontal spacing of holes were $10 \mathrm{~mm}$ and $20 \mathrm{~mm}$. In addition, the size of the models was also the same as the above.

4.2. Effect of Hole Diameter on Energy Evolution of Coal Samples. According to scheme one, four kinds of numerical models were built and later uniaxial compression tests were simulated by PFC2D. Numerical simulation results are shown in Figure 5. In the numerical model, in order to characterize the effect of various hole diameters on energy evolution, the concept of hole area index $K$ was proposed. It was the ratio of circular area to numerical model area which was used to describe the size of the hole area in the unit area of the coal sample.

In Figure 4, under uniaxial compression, the strain energy evolution of CSPHD has a similar growing tendency with intact coal specimen. During the initial stage, the external force was small enough and strain energy slowly increased. The strain energy-strain curve was expressed as a concave curve. During increasing loading, a considerable amount of energy was stored in coal element and the strain energy linearly increased. When the peak strength was reached, it reached the maximum value, which was named as energy storage limit (ESL) in this paper which the coal sample can store. At the postpeak stage, the strain energy quickly reduced and coal specimen was destroyed. At this stage, the number of new microcracks quickly increased and some strain energy accumulated in the coal element turned into fracture energy accompanying by a large energy release. Moreover, with a different hole diameter, the strain energy evolution of the coal specimen had a different trend (Figure 5). At the prepeak stage, with the increase in $K$, namely, the hole diameter increasing, the growth rate of strain energy decreased. At the same time, the ESL linearly decreased, as shown in Figure 5. At the postpeak stage, when $K$ was 0.2512 or 4.0192, the strain energy reduced rapidly was released. By contrast, when $K$ was 1.0048 or 2.2608 , the strain energy slowly reduced at the postpeak stage. Bear in mind that especially when $K$ was 2.2608 , the falling trend of the strain

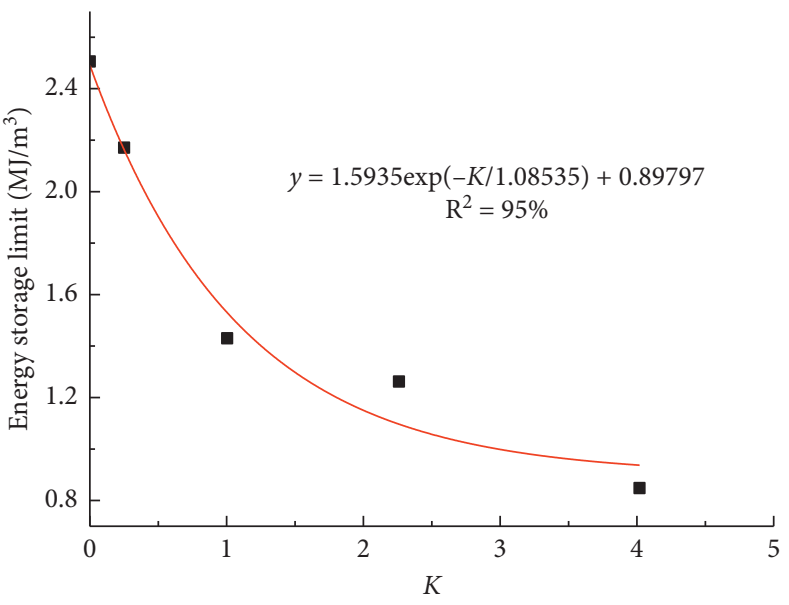

FIGURE 5: Relationship of the ESL and $K$.

energy appeared more prominent. It can be deduced that the strain energy was slowly released when the preexisting hole was $12 \mathrm{~mm}$ in diameter.

In Figure 6, at the postpeak stage, the dissipation energy has a different growing tendency with the increase in $K$. When $K$ was 0.2512 , the dissipation energy increased in a similar trend with intact coal specimen (Figure 7), and the number of cracks also developed quickly (Figure 7). This meant that the energy that was used to promote initiation, development, and coalescence of cracks was almost the same. However, with the increase in $K$, especially when $K$ was 0.2512 or 4.0192 , the dissipation energy slowly increased and the maximum value decreased. At the same time, the cracks periodically developed. It can be deduced that the coal specimen was lightly destroyed by cracks. When $K$ was 2.2608 , the dissipation energy was $0.86 \mathrm{kN} \cdot \mathrm{m}$ which was $30 \%$ of that of intact coal specimen. But the growth tendency of dissipation energy and the cumulative number of cracks were almost the same as that of intact coal specimen. It meant that once the diameter of the preexisting hole reaches the limit value that the coal specimen can bear, the crack developed in similar velocity and it might be destroyed like intact coal specimen.

According to the above simulation results, it can be concluded that if the preexisting hole was in appropriate diameter, such that $K$ was 2.2608 , the strain energy accumulation and release can be reduced at the postpeak stage.

4.3. Effect of Hole Vertical Spacing Size on Energy Evolution of Coal Samples. According to scheme two, five kinds of numerical models containing different vertical spacing were built. The strain energy evolution curve was shown in Figure 8. In order to characterize the effect of hole vertical spacing size, the concept of hole spacing index $m$ was also proposed. It was expressed as the ratio of the distance between two vertical holes to the height of coal specimen. It described the distribution density of holes in the vertical direction of coal sample.

In Figure 9, under uniaxial compression, the strain energy evolution had the same variation trend. However, 


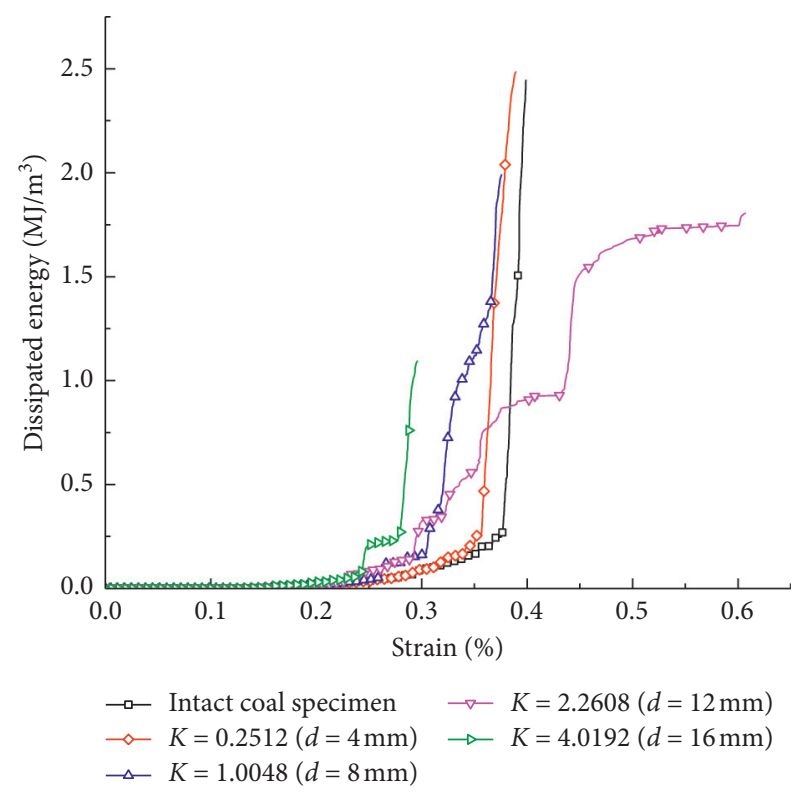

Figure 6: Curve of dissipated energy $U_{d}$ and strain.

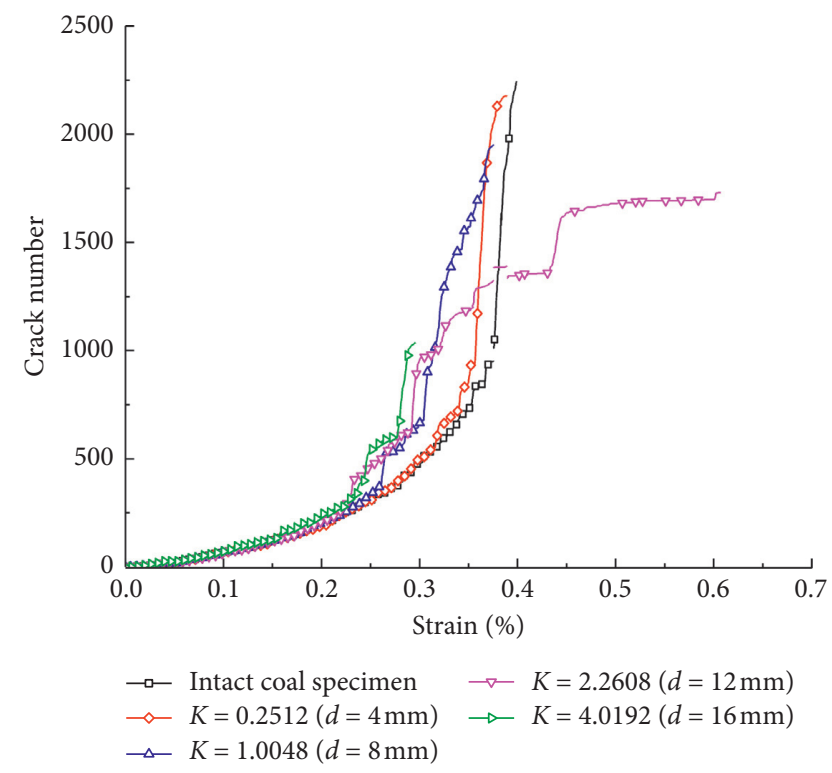

FIGURE 7: Curve of crack number and strain.

with the increase in hole spacing, the strain energy growth rate decreased. At the prepeak stage, the strain energy slowly increased and then linearly increased to ESL. Once the strain energy exceeded the ESL, the coal specimen was destroyed and the strain energy was released. At the past-peak stage, when $m$ was 0.25 or 0.05 , the strain energy quickly decreased in a form of that of intact coal specimen which meant that the strain energy was violently released. Moreover, as shown in Figure 10, with increase in $m$, the ESL of CSPHD was less than that of intact coal specimen. At the same time, the ESL increased at first and then decreased (In Figure 8). Bear in mind that when $m$ was from 0.1 to 0.15 , the ESL reached the minimum value, which was about $1.4 \mathrm{kN} \cdot \mathrm{m}$. It can be deduced that only when $m$ was from 0.1 to 0.15 , the ESL of

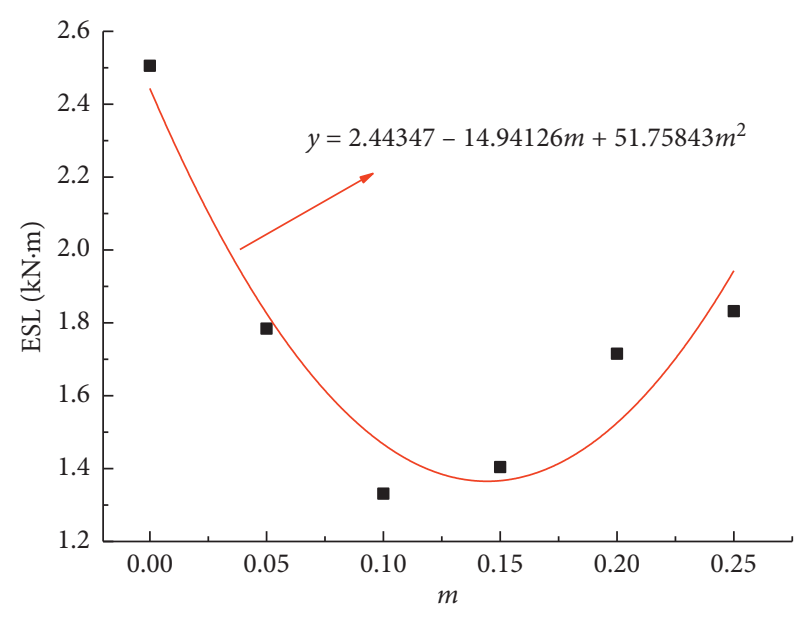

FIgUre 8: Relationship of the ESL and hole spacing index $m$.

CSPHD can be reasonably weakened and the strain energy was slowly released.

In Figure 10, at the prepeak stage, the energy dissipation was about $0.5 \mathrm{KN} \cdot \mathrm{m}$ and the cumulative number of cracks was about 750 . It meant that a small part of the total energy was dissipated in the form of surface energy and frictional energy, most parts of the total energy were stored in CSPHD, and the existing holes might not improve the coal's ability to dissipate energy at the prepeak stage. At the postpeak stage, both the cumulative number of cracks and the dissipation energy are more than twice those at the prepeak stage (Figure 11). In addition, when $m$ was 0.05 or 0.25 , the cumulative number of cracks and the dissipation energy increased rapidly. By contrast, when $m$ was 0.10 or 0.15 , the number of cracks increased in the periodic stage and the dissipation energy increased fairly slowly. In other words, at the prepeak stage, when the vertical spacing was $10 \mathrm{~mm}$ or $15 \mathrm{~mm}$, the energy, which was used to promote the initiation, growth, and development of cracks, was smaller than others, and the CSPHD was lightly cut into fragments by cracks.

According to the simulation results, it can be concluded that reasonable controlling of hole vertical spacing might reduce the ESL of coal specimen and weaken brittle fracture, especially when hole vertical spacing was $10 \mathrm{~mm}$ or $15 \mathrm{~mm}$.

4.4. Effect of Holes Relative Angle on Energy Evolution of Coal Samples. According to scheme three, four kinds of numerical models containing different hole relative angle were built. The strain energy evolution curve was shown in Figure 12.

In Figure 12, at the prepeak stage, the strain energy has a similar growth rate. Near the peak stress, the strain energy linearly increased to ESL and the maximum value of ESL was $2.24 \mathrm{kN} \cdot \mathrm{m}$. However, when the hole relative angle was $30^{\circ}$, the $\mathrm{ESL}$ reduced to $1.83 \mathrm{KN} \cdot \mathrm{m}$. When the hole relative angle increased to $90^{\circ}$, the ESL kept mostly unchangeable, as shown in Figure 13. At the postpeak stage, with the increase in the hole relative angle, the strain energy was released quickly. By contrast, as shown in Figure 13, when the hole 


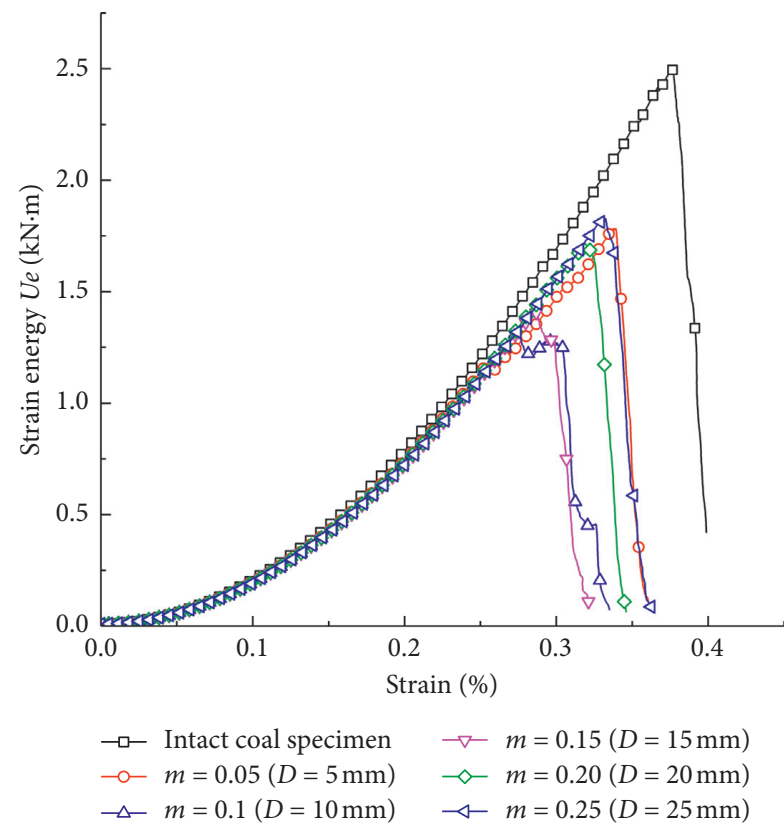

Figure 9: Curve of strain energy $U_{e}$ and strain.

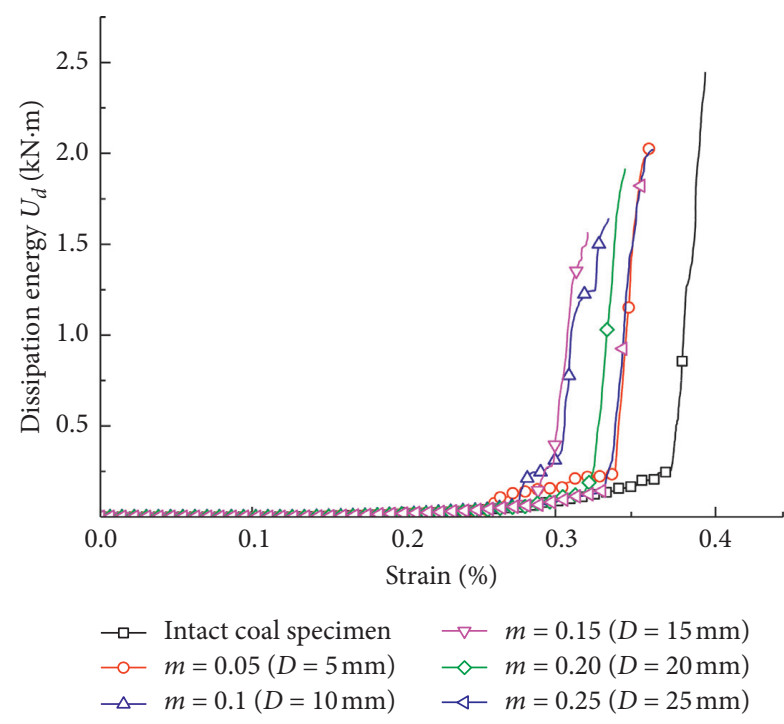

Figure 10: Curve of dissipated energy and strain.

relative angle was $60^{\circ}$, the strain energy reduced in a progressive form meant that the strain energy was released slowly.

In Figure 14, at the postpeak stage, with the variation of the hole relative angle, the energy dissipation was different. When the hole relative angle was $0^{\circ}, 30^{\circ}$, and $90^{\circ}$, respectively, the energy dissipation of CSPHD increased in the same form of intact coal specimen. However, when the hole relative angle was $60^{\circ}$, there was a platform in the dissipated energy-strain curve which meant that the dissipated energy increased slowly. This phenomenon also can be identified in Figure 15. Obviously, when the relative angle between two holes reached $60^{\circ}$, the cumulative

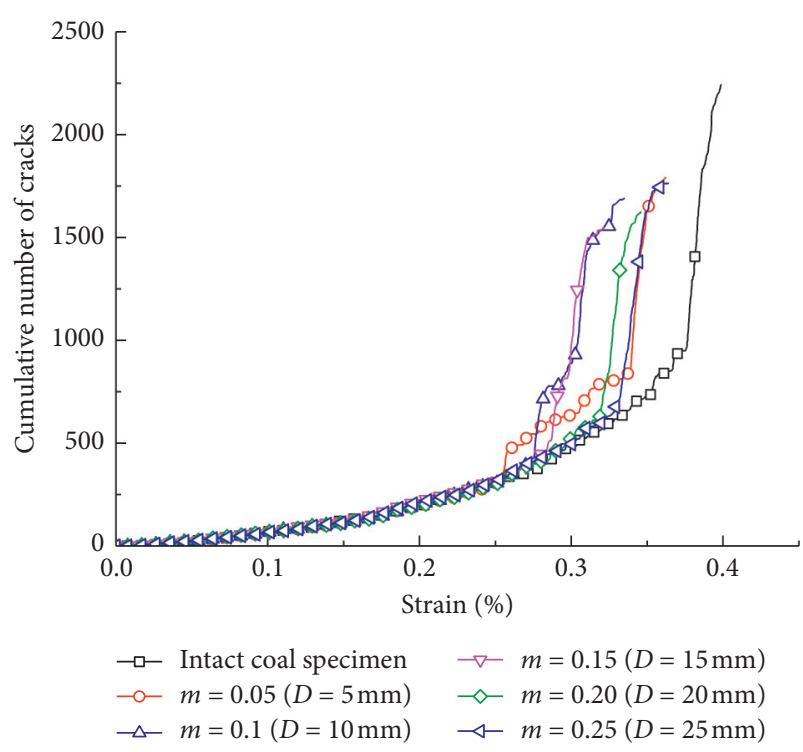

FIGURE 11: Curve of crack number and strain.

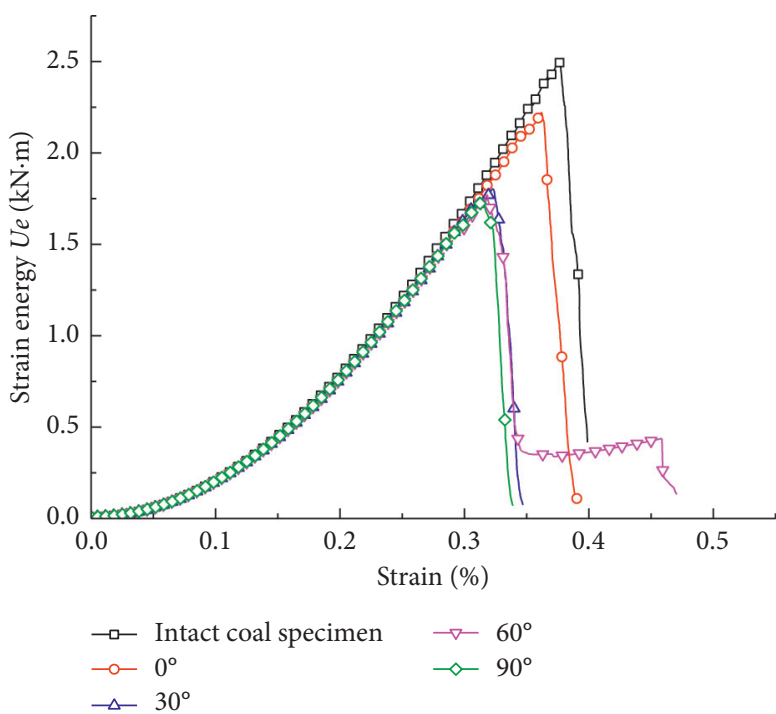

FIgURE 12: Curve of strain energy and strain.

number of cracks increased slowly. It can be deduced that when the hole relative angle was $60^{\circ}$, there was a small part of energy dissipated in the form of surface energy to develop cracks and the coal specimen was slightly cut into fragments. As shown in Figure 16, when the hole relative angle was $60^{\circ}$, the failure patterns of the specimen are mainly characterized by one macroscopic fracture along the inclined plane. By contrast, when the hole relative angle was $0^{\circ}, 30^{\circ}$, and $90^{\circ}$, respectively, the coal specimen was cut into a large number of fragments. It meant that the failure patterns of coal specimen transited from brittle fracture to shear fracture.

According to the above simulation results, when the relative angle of the hole increased to $60^{\circ}$, the ESL can be 


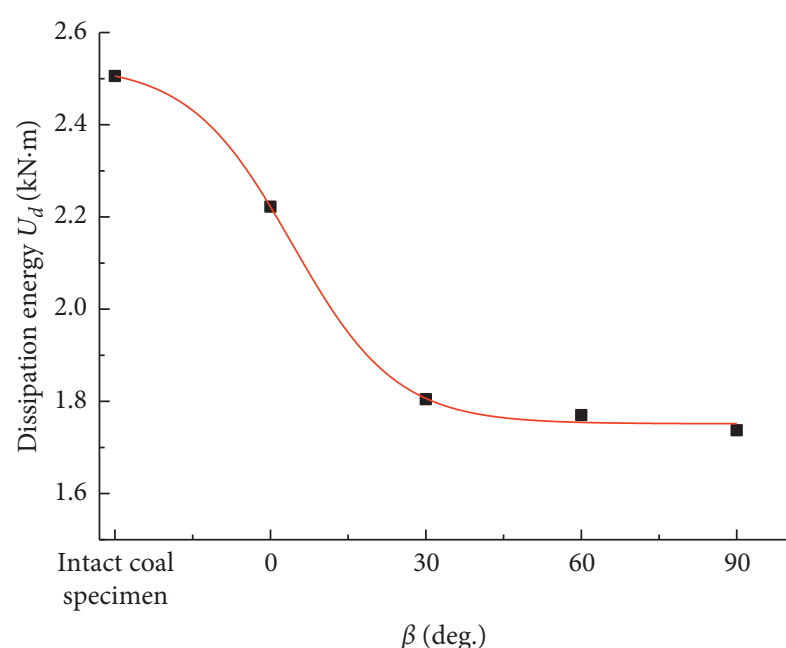

FIgURE 13: Relationship of the ESL and hole angle.

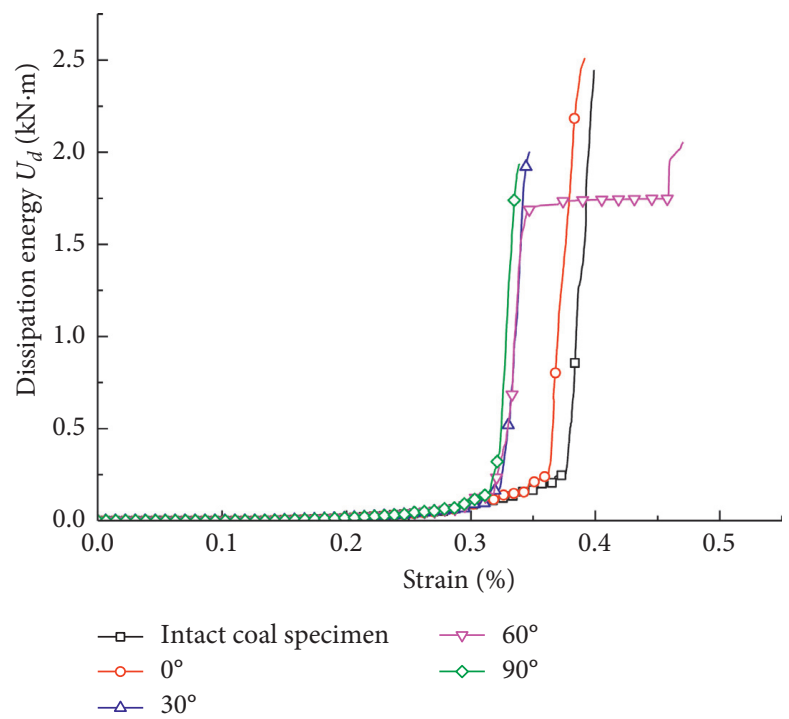

Figure 14: Curve of dissipated energy and strain.

reduced and the failure patterns of the specimen can be transited from brittle fracture to shear fracture.

4.5. Effect of the Hole Number on Energy Evolution of Coal Samples. According to scheme four, four kinds of numerical models were built. The strain energy evolution curve was shown in Figure 17.

In Figure 17, at the prepeak stage, with the increase in the number of holes, the growth rate of strain energy was different under uniaxial compression. At the postpeak stage, the strain energy decreased quickly. In addition, as shown in Figure 18, the ESL linearly decreased. When the number of holes was four, the ESL was $1.59 \mathrm{KN} \cdot \mathrm{m}$, which was nearly two-thirds of the intact coal specimens. It can be deduced that increasing the number of holes can weaken the capacity of coal specimen to store the energy.

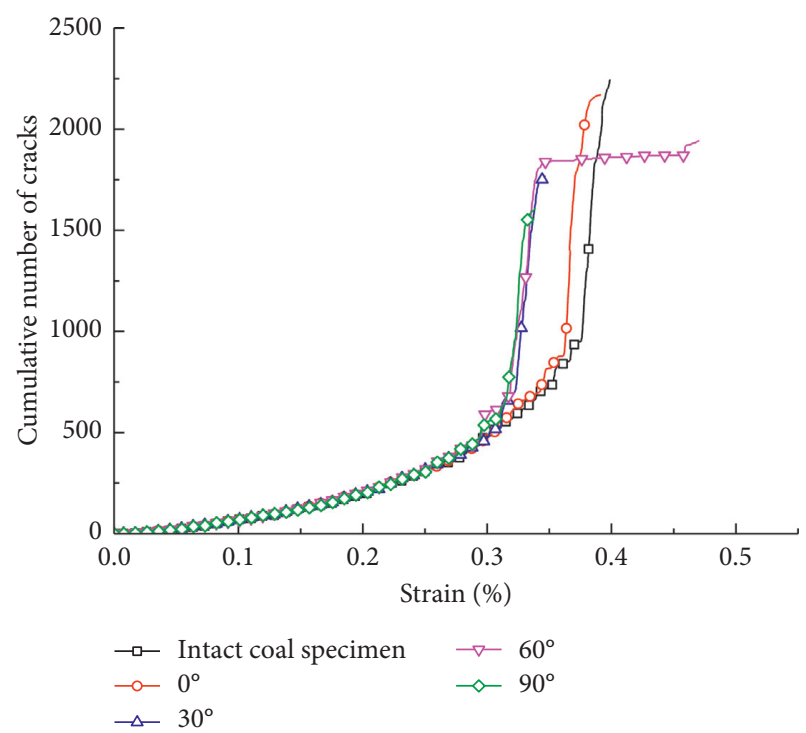

FIgURE 15: Curve of crack number and strain.

As shown in Figure 19, at prepeak stage, with the increase in the number of holes, the dissipation energy was almost the same, which was about $0.25 \mathrm{KN} \cdot \mathrm{m}$. It meant that the energy was used to promote the development of cracks which was almost the same. So, the cumulative number of cracks increased at almost the same speed (Figure 20). At postpeak stage, the energy dissipation increased and the cumulative number of cracks quickly increased. However, when the number of holes was four, the energy dissipation was $1.83 \mathrm{KN} \cdot \mathrm{m}$, which was nearly four-fifth of the intact coal specimen. The cumulative number of cracks was 1521, which were nearly two-thirds of the intact coal specimens. It meant that the increase in the number of holes can reduce the development of cracks at the postpeak stage and the coal specimen was slightly cut into fragments by these cracks. As shown in Figure 21, with the increase in the number of holes, the fragmentation size of damaged coal specimen was relatively small. Especially when the number of holes was four, three inclined macrofailure planes were formed and the failure pattern was shear failure. Due to the increase in the number of holes, the failure degree of coal specimen was significantly weakened.

According to the above simulation results, increasing the number of holes not only reduced the ESL but also retarded the failure degree of coal specimen.

\section{Discussion}

From the above results of numerical simulations, it was clearly demonstrated that different hole arrangement can weaken the ESL of coal specimen. Preexisting holes reduced the stress threshold of crack initiation stress. At the prepeak stage, coal mass was vulnerable to suffer the damage, and then some energy was dissipated to promote the initiation of the cracks. Clearly, the strength, ESL, and strain energy release of coal specimen was reduced. For example, as shown in Figures 6 and 19, with the increase in the diameter and 


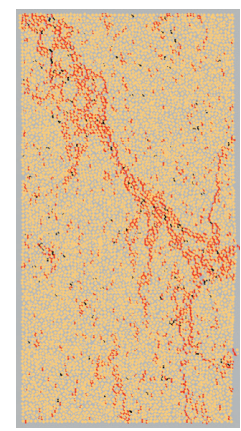

(a)

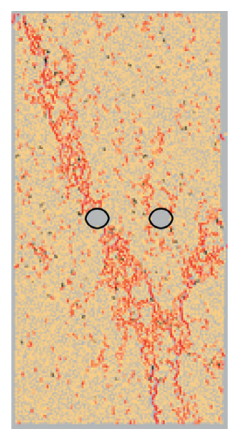

(b)

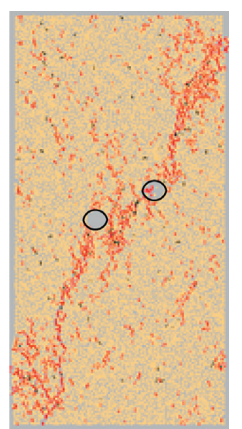

(c)

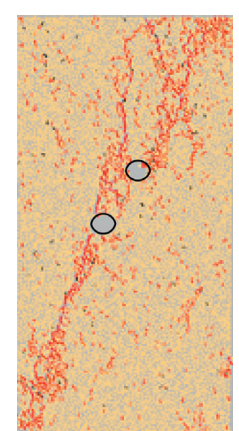

(d)

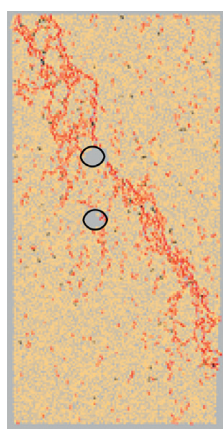

(e)

FIGURE 16: Macrofracture morphology of coal sample with different hole angle. (a) Intact coal specimen, (b) $\beta=0$, (c) $\beta=30^{\circ}$, (d) $\beta=60^{\circ}$, and (e) $\beta=90^{\circ}$.

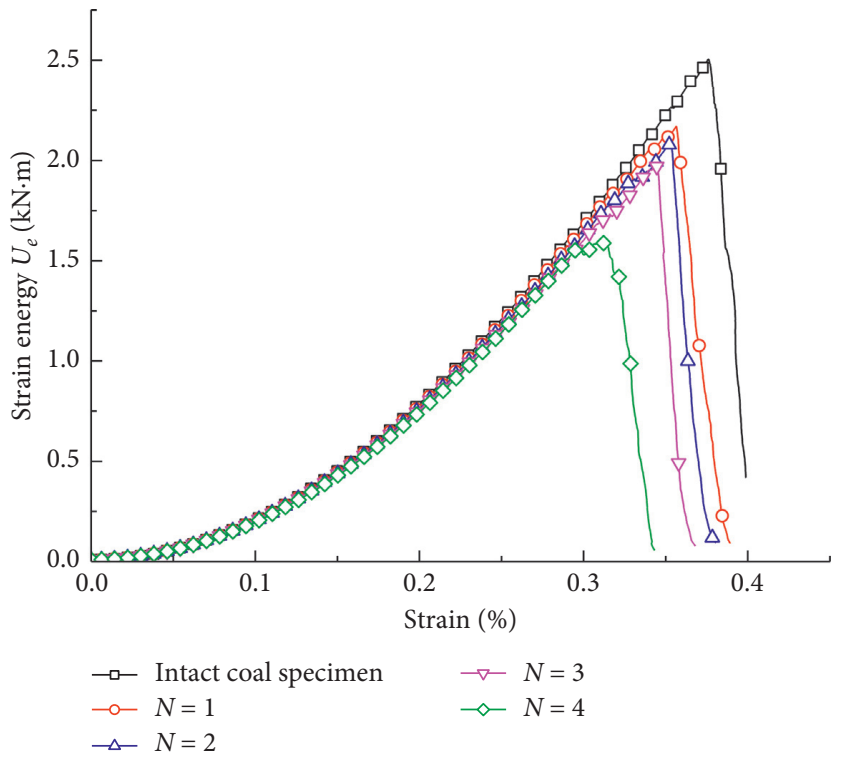

FIGURE 17: Curve of strain energy and strain.

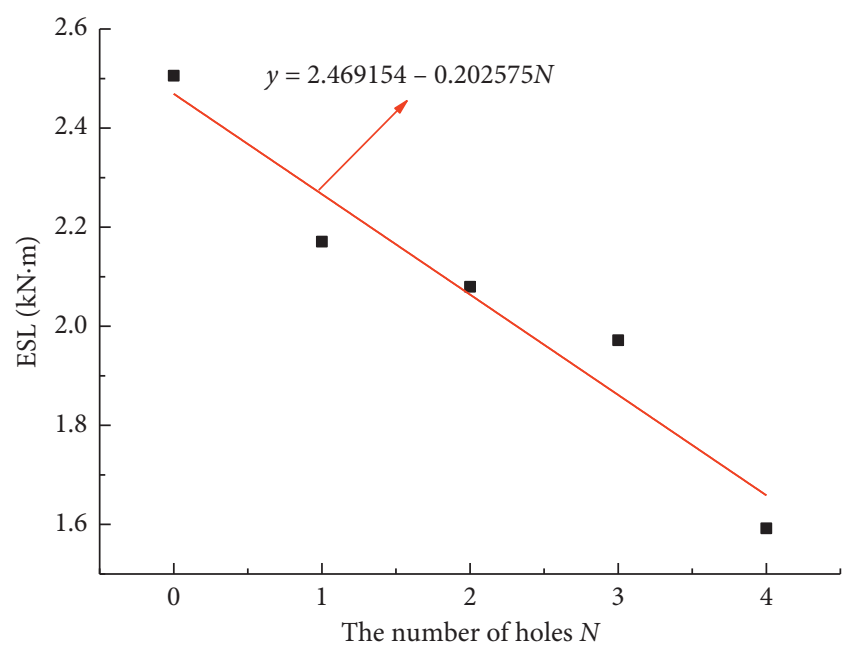

FIgURE 18: Relationship between the ESL and hole number.

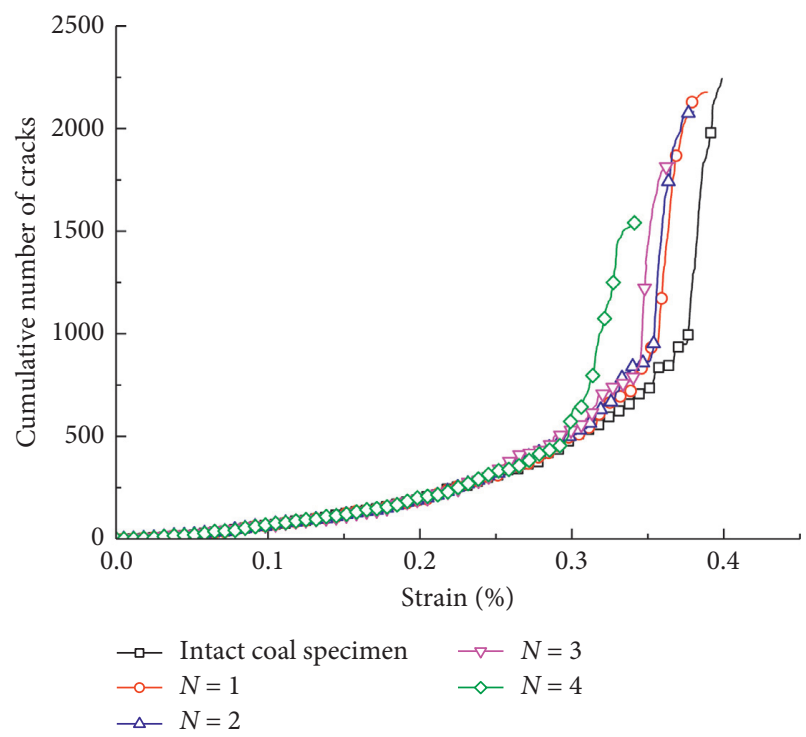

Figure 19: Curve of dissipated energy and strain.

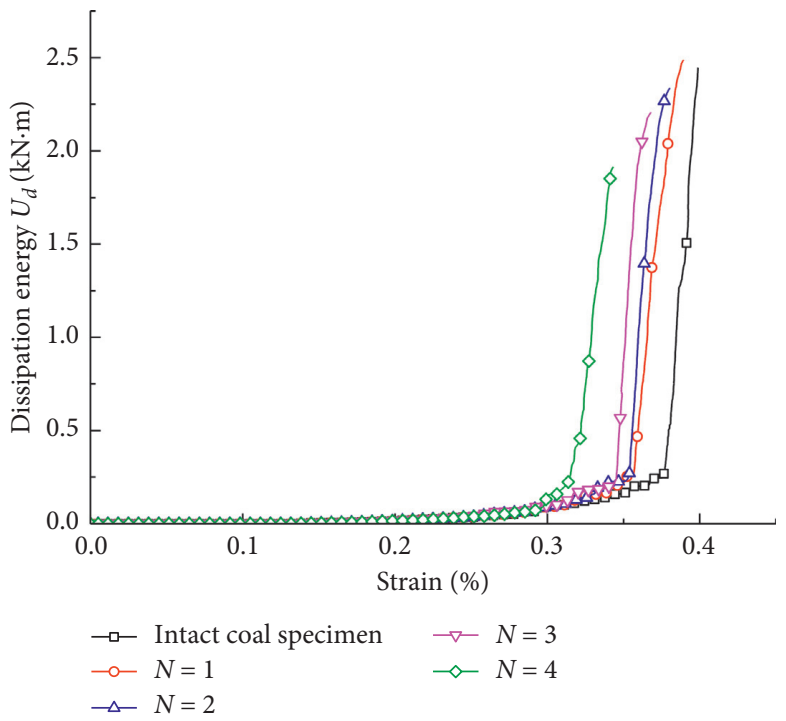

FIGURE 20: Curve of crack number and strain. 


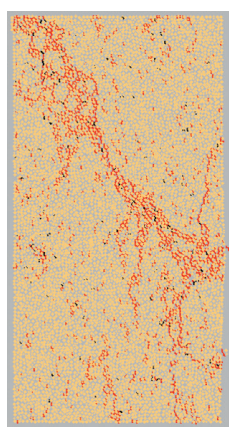

(a)

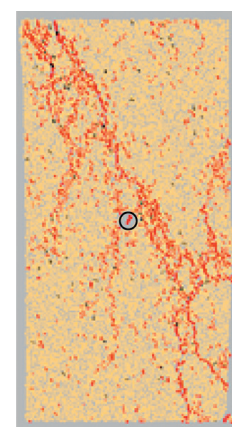

(b)

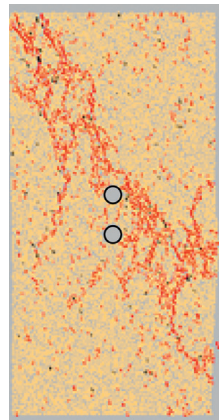

(c)

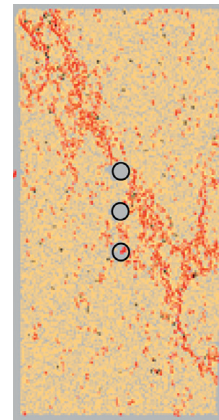

(d)

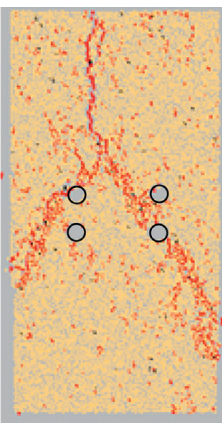

(e)

FiguRe 21: Macrofracture morphology of coal sample with different hole number. (a) Intercoal specimen, (b) $N=1$, (c) $N=2$, (d) $N=3$, and (e) $N=4$.

number of the holes, the ESL linearly increased. In addition, with the increase in the vertical distance, the ESL increased at first and then decreased, and when the vertical distance was $10 \mathrm{~mm}$ or $15 \mathrm{~mm}$, the ESL reached the minimum value (Figure 10). Moreover, when the hole relative angle increased to $60^{\circ}$, the ESL almost kept unchangeable. It is not difficult to find that there are the optimum ranges of some parameters, such as the diameter and spacing of boreholes. When the hole area index was 0.035325 , the hole spacing index was $0.1 \sim 0.15$, the relative angle of boreholes was $60^{\circ}$, and the ESL reached the best values. Those conclusions have a guiding significance in designing the arrangement of the artificial boreholes for mitigation of rockburst.

For the deep coal seam, the large in situ stress endows the coal seam with high strain energy, and the advancement of the longwall face would also enlarge the strain energy of coal seam [26]. During the entire deformation and failure of coal seam, part of the accumulated energy is dissipated to promote the initiation and development of cracks, and the rest of the energy was stored in coal seam in the form of strain energy. Once the strain energy exceeds the ESL, this energy will be quickly released in the form of kinetic energy. If the kinetic energy is large enough, the coal fragments will be ejected at a high speed and the rockburst happens $[7,26]$. It can be deduced that, for weakening the speed of coal fragments, we can take some measures to reduce the ESL. It is widely accepted that the artificial boreholes distressing could decrease the ESL of coal seam [26, 27]. Different arrangement of the artificial boreholes would have different influence on the ESL and energy release. According to the above results of numerical simulations, the arrangement of the artificial boreholes for preventing the rockburst can be reasonably designed. For example, assume that the thickness of coal seam was $x \mathrm{~m}$ and the longitudinal length was $y \mathrm{~m}$. Then, the diameter, spacing, angle, and the number of holes can be obtained. The diameter, spacing, and relative angle of artificial boreholes were $0.035325 x y,(0.1 \sim 0.15) x y$, and $60^{\circ}$, respectively. In addition, the number of artificial boreholes can also be reasonably increased. However, since those designed parameters were only theoretically calculated, those parameters should be suitably adjusted according to the field condition for successfully mitigating the rockburst hazard.

\section{Conclusion}

On the basis of laboratory rock mechanics test and numerical simulation, this paper studied the energy accumulation law of coal specimen containing different arrangement of hole under uniaxial compression and discussed the application in designing the arrangement of the artificial boreholes for preventing the rockburst. The results of the investigations presented in this paper can be summarized as follows:

(1) The microparameters of the PFC model were calibrated according to the existing laboratory tests. These results have a good agreement with laboratory test results and the numerical results duplicated the brittle failure under uniaxial compression. The minimum error of the corrected USC was $6.04 \%$ and the maximum error of the corrected friction angle was only $19.04 \%$.

(2) Under uniaxial compression, different arrangement of preexisting holes has an influence on the ESL and energy release. With the increase in the diameter and number of holes, the ESL linearly increased; with the increase in the vertical distance, the ESL increased at first and then decreased; when the vertical distance was $10 \mathrm{~mm}$ or $15 \mathrm{~mm}$, the ESL reached the minimum value (Figure 10); and when the hole relative angle increased to $60^{\circ}$, the ESL almost kept unchangeable. In addition, when the hole area index was 0.035325 , the hole spacing index was $0.1 \sim 0.15$, the relative angle of boreholes was $60^{\circ}$, and the ESL reached optimal value.

(3) This study has a guiding significance in designing the arrangement of the artificial boreholes for preventing the rockburst. The diameter, spacing, and relative angle of artificial boreholes were $0.035325 x y$, $(0.1 \sim 0.15) x y$, and $60^{\circ}$, respectively. In addition, the number of artificial boreholes can also be reasonably increased.

\section{Data Availability}

The research data used to support the findings of this study are included within the article. 


\section{Conflicts of Interest}

The authors declare no conflicts of interest regarding the publication of this paper.

\section{Acknowledgments}

The research described in this paper was financially supported by the Engineering Laboratory of Deep Mine Rockburst Disaster Assessment Open Project (LMYK2020009).

\section{References}

[1] D. Song, E. Wang, J. Xu, X. Liu, R. Shen, and W. Xu, "Numerical simulation of pressure relief in hard coal seam by water jet cutting," Geomechanics and Engineering, vol. 8, no. 4, pp. 495-510, 2015.

[2] A. Y. Cao, L. M. Dou, W. Cai, S. Gong, S. Liu, and Y. Zhao, "Tomographic imaging of high seismic activities in underground island longwall face," Arabian Journal of Geosciences, vol. 9, no. 3, pp. 1-10, 2016.

[3] N. G. W. Cook, "A note on rockburst considered as a problem of stability," Journal of the South African Institute of Mining and Metallurg, vol. 65, no. 8, pp. 437-446, 1965.

[4] C. Mark, "Coal bursts in the deep longwall mines of the United States," International Journal of Coal Science \& Technology, vol. 3, no. 1, pp. 1-9, 2016.

[5] S. P. Singh, "Burst energy release index," Rock Mechanics and Rock Engineering, vol. 21, no. 2, pp. 149-155, 1988.

[6] G. A. Zhu, L. M. Dou, Z. L. Li, W. Cai, Y. Kong, and J. Li, "Mining-induced stress changes and rock burst control in a variable-thickness coal seam," Arabian Journal of Geosciences, vol. 9, no. 5, pp. 1-12, 2016.

[7] Y. Fan, W. Lu, Y. Zhou, P. Yan, Z. Leng, and M. Chen, "Influence of tunneling methods on the strainburst characteristics during the excavation of deep rock masses," Engineering Geology, vol. 201, pp. 85-95, 2016.

[8] U. Marek, "Monitoring of methane and rockburst hazards as a condition of safe coal exploitation in the mines of Kompania Weglowa SA," Procedia Earth and Planetary Science, vol. 1, no. 1, pp. 54-59, 2009.

[9] L.-M. Dou, C.-P. Lu, Z.-L. Mu, and M.-S. Gao, "Prevention and forecasting of rock burst hazards in coal mines," Mining Science and Technology (China), vol. 19, no. 5, pp. 585-591, 2009.

[10] J. Ning, J. Wang, Y. Tan, and X. Shi, "Dissipation of impact stress waves within the artificial blasting damage zone in the surrounding rocks of deep roadway," Shock and Vibration, vol. 2016, Article ID 4629254, 13 pages, 2016.

[11] L. M. Xie, W. C. Zhu, S. H. Wang, and L. Niu, "Three-Dimensional parallel computing on failure process of rock specimen with a pre-existing circular opening," Chinese Journal of Geotechnical Engineering, vol. 33, no. 9, pp. 1447-1455, 2011.

[12] C. Zhao, H. Matsuda, C. Morita, and M. R. Shen, "Study on failure characteristic of rock-like materials with an open-hole under uniaxial compression," Strain, vol. 47, no. 5, pp. 405-413, 2011.

[13] Q. Zheng, Y. Xu, H. Hu, J. Qian, Y. Ma, and X. Gao, "Quantitative damage, fracture mechanism and velocity structure tomography of sandstone under uniaxial load based on acoustic emission monitoring technology," Construction and Building Materials, vol. 272, Article ID 121911, 2021.
[14] A. Fakhimi, F. Carvalho, T. Ishida, and J. F. Labuz, "Simulation of failure around a circular opening in rock," International Journal of Rock Mechanics and Mining Sciences, vol. 39, no. 4, pp. 507-515, 2002.

[15] D. Y. Li, X. B. Li, C. L. Li, and L. N. Y. Wong, "Experimental and numerical studies of mechanical response of plate-shape granite samples containing prefabricated holes under uniaxial compression," Chinese Journal of Rock Mechanics and Engineering, vol. 30, no. 6, pp. 1198-1206, 2011.

[16] S. Q. Yang and Y. H. Huang, "Experiment and particle flow simulation on crack coalescence behavior of sandstone specimens containing double holes and a single fissure," Journal of Basic Science and Engineering, vol. 2, no. 3, pp. 584-597, 2014.

[17] J. H. Liu, F. X. Jiang, G. J. Sun et al., "Mechanism of intensive venting pulverized coal to prevent coal burst and its application," Chinese Journal of Rock Mechanics and Engineering, vol. 4, no. 4, pp. 747-754, 2014.

[18] P. Lin, R. H. C. Wong, and C. A. Tang, "Experimental study of coalescence mechanisms and failure under uniaxial compression of granite containing multiple holes," International Journal of Rock Mechanics and Mining Sciences, vol. 77, pp. 313-327, 2015.

[19] N. Cho, C. D. Martin, and D. C. Sego, "A clumped particle model for rock," International Journal of Rock Mechanics and Mining Sciences, vol. 44, no. 7, pp. 997-1010, 2007.

[20] R. H. C. Wong, P. Lin, and C. A. Tang, "Experimental and numerical study on splitting failure of brittle solids containing single pore under uniaxial compression," Mechanics of Materials, vol. 38, no. 1-2, pp. 142-159, 2006.

[21] M. S. Zhang, S. H. Wang, and Y. Q. Yang, "Numerical simulation of jointed rock mass constitutive model and its validation," Engineering Mechanics, vol. 28, no. 5, pp. 26-30, 2011.

[22] ISRM, Rock Characterization Testing and Monitoring, Pergamon Press, Oxford, UK, 1986.

[23] J. F. Hazzard, R. P. Young, and S. C. Maxwell, "Micromechanical modeling of cracking and failure in brittle rocks," Journal of Geophysical Research: Solid Earth, vol. 105, no. B7, pp. 16683-16697, 2000.

[24] Itasca Consulting Group Inc, Manual of Particle Flow Code in 2-Dimension (Version 3.10), Itasca Consulting Group Inc, Minneapolis, MN, USA, 2004.

[25] C. Zhao, B. E. Hobbs, A. Ord, P. Hornby, S. Peng, and L. Liu, "Particle simulation of spontaneous crack generation problems in large-scale quasi-static systems," International Journal for Numerical Methods in Engineering, vol. 69, no. 11, pp. 2302-2329, 2007.

[26] H. W. Wang, Y. D. Jiang, and J. Zhu, "Numerical investigation on the assessment and mitigation of coal bump in an island longwall panel," International Journal of Mining Science and Technology, vol. 23, no. 5, pp. 625-630, 2013.

[27] Y. L. Tan and Z. Zhang, "Rock burst disaster induced by mining abutment pressure," Disaster Advances, vol. 5, no. 4, pp. $378-382,2012$. 